\title{
DESIGUALDADE SOCIAL E O DIREITO À EDUCAÇÃO NO BRASIL: REFLEXÕES A PARTIR DA REFORMA DO ENSINO MÉDIO
}

\author{
Marcilene Pelegrine Gomes \\ Universidade Federal de Goiás (UFG), Goiânia, Goiás, Brasil \\ Aldimar Jacinto Duarte \\ Pontifícia Universidade Católica de Goiás (PUC Goiás), Goiânia, Goiás, \\ Brasil
}

\begin{abstract}
Resumo: Este estudo tem como objetivo analisar as implicações políticas e pedagógicas da Reforma do Ensino Médio no Brasil, instituída pela Lei n. 13.415 de fevereiro de 2017, e a garantia do direito à educação, considerando as interfaces entre a desigualdade social e a desigualdade educacional. Para tanto, buscou-se apreender, no campo das teorias sociais, as discussões em torno dos conceitos de justiça social, cidadania e direito à educação, tomando como referência os estudos de Anderson (2002), Bourdieu (2001), Ciavatta (2005), Dubet (2008), Fernandes (1960), Frigotto $(2005,2017)$ Marshal (1988), Marx (2010), Oliveira (2003) Rawls (2000).
\end{abstract}

Palavras-chave: Desigualdade social. Direito à educação. Reforma do Ensino Médio.

\section{INTRODUÇÃO}

$\mathrm{Na}$ contemporaneidade, o crescimento da pobreza, da exclusão e da desigualdade social entre os homens e nações impõe o exercício teórico e empírico de se compreender as bases epistemológicas e políticas que sustetam o desenvolvimento material e espiritual das sociedades ocidentais. Esse exercício intelectual e político pressupõe problematizar o modelo econômico que, ao produzir mercadorias, produz modos de vida fundamentados na exploração e na subordinação objetiva e subjetiva do homem, sendo a educação formal um dos instrumentos possíveis para a conformação ou a emancipação humana. Daí a importância de se pensar criticamente as políticas educacionais para educação básica.

Nesse sentido, buscou-se neste artigo, por meio do estudo bibliográfico e documental, apreender, de forma geral, os nexos entre desigualdade social, cidadania e direito à educação no mundo ocidental e, de forma específica, compreender os limites do 
Estado brasileiro em implementar políticas educacionais que assegurem, no plano formal e social, o direito à educação. Para tanto, tomou-se como objeto de reflexão e problematização a Reforma do Ensino Médio, instituída pela Lei n. 13.415 de fevereiro de 2017, e as implicações políticas e pedagógicas para educação básica.

Para fins de exposição, o estudo foi dividido em duas sessões que se articulam e se complementam em torno do tema central, qual seja: desigualdade social, cidadania, direito à educação e reforma do ensino médio no Brasil. Na primeira sessão, procurou-se, a partir de Marshal (1988), apreender o conceito de cidadania no contexto da modernidade ocidental, bem como explicitar e analisar o conceito de justiça social elaborado pelo pensador liberal norte-americano J ohn Rawls (2000). Na segunda sessão, procurou-se tecer algumas reflexões acerca da desigualdade social no Brasil e o desdobramento no campo educacional, com ênfase na análise dos pontos centrais da Reforma do Ensino Médio de 2017.

\section{DIREITOS SOCIAISE A DESIGUALDADE ACEITÁVEL}

Na modernidade, a desigualdade social foi se constituindo como uma das características principais das so ciedades ocidentais capitalistas. 0 aumento da pobreza ou do pauperismo dos trabalhadores fez emergir um conjunto de conflitos sociais que suscitaram disputas políticas e epistemológicas em torno das concepções de sociedade, modelo produtivo e do papel do Estado diante da fragilidade e miserabilidade dos trabalhadores. No campo do pensamento social, essas disputas sintetizam posicionamentos teóricos divergentes e, em grande medida, antagônicos entre os pensadores liberais e os sociais-críticos (ANDERSON, 2002).

Para o pensamento liberal-burguês, a categoria igualdade foi tomando a forma do discurso da equidade, ou seja, de uma desigualdade suportável que não significaria, no campo político e econômico, uma ameaça para a reprodução do sistema capitalista. Nesse contexto, os próprios conceitos de cidadania e justiça social foram construídos a partir da lógica de redução das ameaças sociais, e menos no sentido de proporcionar a igualdade de direitos e de oportunidades tão almejadas pelos setores progressistas.

No século XIX, a promessa liberal burguesa de garantia dos direitos de cidadania política e cidadania civil não foi suficiente para garantir a coesão e a estabilidade social necessárias para o desenvolvimento do modo de produção capitalista. Na Europa, a partir da ação política de contestação dos trabalhadores, alguns Estados passaram gradativamente a desenvolver ações e legislações com foco na cidadania social. Essas ações tinham por objetivo proporcionar alguns direitos sociais reivindicados pelos trabalhadores, pois considerava-se que a cidadania civil e política, por si, não assegurava a mínima participação dos indivíduos na riqueza coletiva e, por conseguinte, não atenuava o conflito social existente.

Nesse sentido, ser cidadão passou a ser compreendido e disputado como o direito à vida, à liberdade, à propriedade, à igualdade perante a lei (direitos civis), à participação no destino da sociedade, votar, ser votado (direitos políticos) e, no acesso aos bens materiais e simbólicos produzidos pela sociedade, como o direito à educação, 
ao trabalho, ao salário justo, à saúde e a uma velhice tranquila (cidadania social). Assim, exercer a cidadania plena passou a ser compreendido como o exercício dos direitos civis, políticos e sociais, distante, no entanto, de se almejar uma igualdade completa, como se postulava nas perspectivas socialistas, proporcionando uma melhoria das condições de vida, em especial do trabalhador.

Marshal (1988) caracteriza essas três dimensões de direito em cidadania civil, cidadania política e cidadania social, considerando que essas dimensões ora se interrelacionam, ora se distanciam. Para o autor, a cidadania civil é composta pelos direitos necessários à liberdade individual (liberdade de ir e vir, liberdade de imprensa, pensamento e fé, o direito à propriedade e de concluir contratos válidos e com o direito à justiça). A cidadania civil é definida, ainda, como o direito de se defender e afirmar todos os direitos em termos de igualdade com os outros. A cidadania política é entendida como o direito de participar no exercício do poder político como um membro de um organismo, investido da autoridade política ou como um eleitor dos membros de tal organismo. Já a cidadania social se refere ao direito dos indivíduos a um mínimo de bem-estar econômico que lhes assegure o direito de participar da herança social.

De acordo com Marshal (1988), nas sociedades feudais essas três dimensões de direitos estavam fundidas numa só, tendo em vista que as próprias instituições estavam diretamente ligadas umas às outras. Os direitos sociais do indivíduo não se separavam dos demais, pois eram originários do status que também determinava que espécie de justiça ele poderia esperar e onde obtê-la, bem como a maneira pela qual participaria da administração dos negócios da comunidade à qual pertencia.

Já no século XVIII, o direito civil se caracterizava por vários aspectos no campo jurídico que definiam as liberdades individuais, entre outros o Habeas Corpuse a abolição da censura da imprensa. No setor econômico, o direito civil básico era o de trabalhar livre do poder dos senhores ou das corporações. 0 indivíduo passava a ser livre para escolher uma ocupação, sujeito apenas à exigência do treinamento técnico preliminar.

Nesse sentido, na modernidade os direitos civis antecederam aos direitos políticos, os quais tiveram seus primeiros ensaios por volta de 1832. Além da distinção temporal, esses direitos se diferenciam também em seu caráter, pois, embora no século XVIII os direitos políticos não fossem destinados a todos os homens, o seu conteúdo era significativo. Segundo Marshal (1988), na Europa ocidental do século XIX, a cidadania civil era universal, contudo os direitos políticos se constituíam ainda em privilégio de uma determinada classe econômica. No contexto da sociedade capitalista do século XIX, os direitos políticos se constituíam em um produto secundário dos direitos civis.

Segundo Marshal (1988), não há dúvida de que, no século XX, o debate em torno da cidadania avançou no sentido de construir uma igualdade liberal-burguesa, ou seja, uma desigualdade suportável, considerando que, para o desenvolvimento do capitalismo, a desiguald ade social se constitui como necessária e proposital ${ }^{2}$. Dessa forma, caberia ao novo modelo de cidadania social não eliminar as desigualdades, mas controlar o seu caráter excessivo.

Historicamente, a ideia de cidadania se constitui como um princípio de igualdade balizada pelos direitos civis, políticos e sociais. No entanto, o desenvolvimento desses direitos não estava em conflito com as desigualdades estruturantes da sociedade capitalista; eram, pelo contrário, necessários à manutenção da ordem econômica, tendo em vista que os direitos civis eram indispensáveis a uma economia de mercado competi 
tivo. No século XX, os direitos sociais foram subordinados à ideia de justiça social. Nesse sentido, as desigualdades poderiam ser toleradas desde que se tivesse, na sociedade capitalista, a igualdade como princípio. Trata-se, portanto, de um conjunto de desigualdades permitidas, moldadas pela próp ria cidadania como parte da concepção de democracia liberal constitucional que se tornou hegemônica no mundo ocidental.

No debate acerca do sentido de justiça social, o estadunidense J ohn Rawls (2000), na obra Uma Teoria da J ustiça, publicada originariamente em 1971, propõe claramente o princípio da Justiça como equidade, uma concepção filosófica para uma democracia liberal constitucional. Para Rawls (2000), a justiça se constitui como a primeira virtude das instituições sociais, sendo que cada pessoa possui uma inviolabilidade fundada na justiça, que nem mesmo o bem-estar da sociedade como um todo pode ignorar. Uma sociedade é uma associação mais ou menos autossuficiente de pessoas que, em suas relações mútuas, reconhecem certas regras de conduta como obrigatórias e que, na maioria das vezes, agem de acordo com elas.

0 autor considera que, embora uma sociedade seja um empreendimento cooperativo visando vantagens mútuas, ela é tipicamente marcada por conflitos e por disputas de interesses. É por esse motivo que se acredita ser necessário estabelecer um conjunto de princípios, entre as várias formas de ordenação social, que determinaria a divisão de vantagens de forma a assegurar acordos e políticas distributivas. Nesta perspectiva, uma sociedade estaria bem-ordenada quando regulada por uma concepção pública de justiça em que todos aceitam e sabem aceitar os mesmos princípios de justiça, e as instituições sociais básicas satisfazem esse princípio.

Nesse sentido, para Rawls (2000), a justiça social é fruto do consenso estabelecido por uma determinada sociedade que define a maneira pela qual as instituições sociais distribuem os direitos e os deveres fundamentais, bem como determina a divisão de vantagens provenientes da cooperação social. Assim, a ideia de justiça social fornece 0 padrão pelo qual se deve avaliar aspectos distributivos da estrutura básica da sociedade. 0 autor considera ainda que 0 conceito de justiça se define pela atribuição de direitos e deveres e pela divisão apropriada de vantagens sociais. Portanto, não parte de uma concepção de justiça universal, mas sim de justiça como equidade, pois a considera como intrinsecamente relacionada aos pactos e consensos de uma sociedade específica, determinada no tempo e no espaço, para manter um nível de desigualdade aceitável, adotando, assim, o sistema da igualdade democrática. Chega-se a este sistema por meio da combinação do princípio da igualdade equitativa de oportunidades com o princípio da diferença.

A crítica mais pertinente em relação à Teoria da Justiça de Rawls está na sua concepção de justiça e igualdade como equidade. Trata-se de uma concepção que não tem como princípio a justiça e a igualdade na totalidade, pois parte da premissa de que 0 justo se constitui como parte de um consenso no qual todos aceitam as suas verdades e regras a partir de um véu da ignorância, e a justiça se realiza, independentemente do produto, com base nos procedimentos e não nos resultados (RAWLS, 2000).

Esse pensamento coaduna-se, em grande medida, com a lógica de funcionamento e reprodução da sociedade capitalista, estruturalmente fundamentada em consensos e procedimentos que naturalizam ou ocultam a desigualdade social. Dessa 
forma, constata-se que os conceitos de igualdade e justiça social, na perspectiva liberal de Rawls (2000), fazem parte de um pacto social que não tem como princípio a construção de uma sociedade efetivamente igualitária, justa, sem classes, mas de uma sociedade que se constitua a partir de uma desigualdade suportável, de uma justiça que, mais do que equalizadora, se convertesse em redução dos conflitos sociais.

É importante destacar que as noções de cidadania e justiça social estão estreitamente relacionadas à concepção de Estado, ou seja, ser cidadão ou ser uma sociedade justa se define em consonância com o papel que o Estado assume em uma determinada sociedade. Entre os séculos XVIII e XX, a discussão sobre cidadania e justiça social encontrava-se no campo de disputa de sentidos entre os setores socialistas e liberais, se constituindo, entretanto, a partir da hegemonia liberal. No século XX, essa disputa continuará acirrada, mas marcada pela hegemonia liberal do Estado de bem-estar social, com a redução dos princípios de igualdade defendidos pelo socialismo.

Não obstante, a partir da década de 1980 essa hegemonia foi substituída por uma nova lógica capitalista mundial, caracterizada por um modelo de globalização fundamentado nos princípios neoliberais, deslocando-se tanto dos princípios socialistas como dos liberais-sociais-democratas. Em nome da acumulação de capital e da centralidade do mercado como organizador da sociedade, a defesa da justiça social, da cidadania e da igualdade foram secundarizadas nos discursos, e sobretudo nas ações dos governos ocidentais (ANDERSON, 2002).

Nesse contexto, entre os fins da década de 1980 e início da de 1990, houve o distanciamento, no âmbito dos Estados nacionais, dos pactos sociais do século XIX e da primeira metade do século XX. Esse fato contribuiu para o agravamento, em escala mundial, da questão social. Assim, o conceito de cidadania, defendido no campo das teorias liberais, tendo como orientação a igualdade como equidade, não se efetivaram no plano da materialidade, a não ser como a retórica eleitoral ou nos tratados firmados a partir da ação de alguns organismos internacionais, bem como em algumas políticas públicas de um reduzido grupo de governos nacionais.

De forma geral, o capitalismo mundial, a partir da década de 1980, se inseriu em uma nova fase de desenvolvimento histórico, em que a noção de cidadania e justiça social ganhou novos contornos na perspectiva de assegurar, sem eliminar a desigualdade social, a equidade possível às minorias historicamente excluídas. Seguindo essa lógica, as políticas educacionais como materialização da ação do Estado foram sendo pensadas e implementadas de acordo com a nova lógica mundializada do capital, ou seja, o atendimento irrestrito à lógica do mercado. No mundo ocidental, a despeito da retórica cidadã e de justiça social, o que se consolidou foi um modelo nacional e internacional pautado na lógica de exclusão e, em grande medida, justificado a partir dos princípios de equidade.

No Brasil, os desafios estruturantes postos à cidadania e à justiça social revelam as contradições de um país em que o direito à educação não se constituiu em projeto de sociedade e de Estado. Na lógica capitalista brasileira, as oportunidades individuais não são orientadas para justiça social, conforme preconizou Rawls (2000). Para ele, numa sociedade onde a justiça seja a primeira virtude de suas instituições, existirá a garantia do desenvolvimento individual e autônomo dos cidadãos por meio da distribuição justa dos bens para que todos tivessem as oportunidades de ter uma boa vida. 
Dessa forma, na compreensão de Rawls (2000), seria possível, numa sociedade capitalista de mercado, garantir, pela mediação do Estado, a justiça social. Mesmo considerando a importância dos estudos desse autor, pensadores sociais críticos, como Anderson (2002), contrapõem-se a essa premissa ao sustentarem que, numa sociedade organizada em classes antagônicas e premida pela competição, pelo lucro e pela exploração da força de trabalho, é impossível a distribuição justa dos bens (materiais e simbólicos), e portanto, impossível também a materialização da justiça social, até mesmo como equidade.

$\mathrm{Na}$ atualidade, no campo das políticas sociais, principalmente no âmbito educacional, a ideia de que todos podem ter as mesmas oportunidades e de que é possível a garantia da justiça social por meio do Estado ou do mercado, tornou-se ainda mais hegemônica. Em contraposição (política e epistemologicamente) a essa compreensão, a teoria crítica de orientação marxista colocou como ponto central no debate sobre justiça social a ideia de emancipação humana. No horizonte de transformação social, só é possível falar de justiça social quando todos os homens forem de fato sujeitos autônomos (ADORNO, HORKHEIMER, 1995).

Para Adorno e Horkheimer (1995), é necessário compreender ontologicamente o conceito de emancipação. Para tanto, faz-se necessário retomar, nos estudos de Karl Marx, sobretudo no livro Sobre a questão judaica, escrito em 1843, o conceito e o sentido de emancipação humana. Para Marx,

[...] não se trata de investigar apenas quem há de emancipar e quem deve ser emancipado. A crítica tem que indagar-se, além disso, outra coisa: de que espécie de emancipação se trata; quais as condições implícitas da emancipação que se postula $(2010$, p. 17).

Na perspectiva materialista dialética, 0 ato de emancipação humana transcende, em conteúdo e forma, a ideia liberal moderna de emancipação política. A emancipação humana refere-se ao pleno desenvolvimento das potencialidades humanas na dimensão ontológica e histórica. O homem emancipado está para além das mudanças e das garantias civis, políticas e institucionais decorrentes da ascensão da burguesia como classe hegemônica, ordenadora da vida material e social no mundo ocidental.

Para Marx (2010), a emancipação política anunciada e defendida pela burguesia no período moderno, representava a consolidação dos direitos civis e políticos, não da totalidade dos homens, mas sim do homem burguês, reafirmando a contradição entre 0 trabalho e o capital, o trabalhador e o patrão, colocando a vida política a serviço da sociedade burguesa. Nessa lógica social, não é possível e necessário o desenvolvimento das múltiplas potencialidades humanas, principalmente da classe trabalhadora.

Para o pensamento crítico, considerando a materialidade histórica, só é possível falar em justiça social na medida em que todos os homens tenham acesso às condições objetivas (materiais) e subjetivas (imateriais) de desenvolvimento humano para além do plano formal e legal. Contudo, a história do capitalismo demonstra a impossibilidade estrutural de assegurar essas condições para que todos os indivíduos conquistem uma 
boa vida, tampouco para que tenham acesso às condições materiais indispensáveis à dignidade humana.

0 discurso liberal em torno da justiça social, sem o confronto rigoroso à desigualdade social, oculta e naturaliza as contradições estruturantes do próprio sistema de produção da vida material e espiritual, prometendo liberdade e oportunidade para todos, sem, contudo, assegurar as condições objetivas para sua efetivação no âmbito da práxis social. Assim, o discurso de equidade, fundamentado na garantia da liberdade, autonomia e oportunidade para todos os indivíduos, não é compatível com o próprio projeto burguês de sociedade, principalmente em tempos de neoliberalismo.

\section{DESIGUALDADE SOCIAL E O DIREITO À EDUCAÇÃO BÁSICA NO BRASIL: A REFORMA DO ENSINO EM DISCUSSÃO}

Tomando para fins de análise as políticas para o ensino médio, se considerarmos que a justiça social não se efetiva sem a emancipação humana (ADORNO, HORKHEIMER, 1995), tampouco com a desigualdade social - característica do modo de produção capitalista - faz-se necessário problematizar, teórica e metodologicamente: em que medida o projeto societário brasileiro conseguiu articular justiça social, cidadania e direito à educação básica? Como falar de justiça social e cidadania num país em que o direito à escola básica ainda não foi universalizado? Como falar em equidade quando as crianças das camadas populares ainda não têm assegurado o direito à educação infantil e os jovens ao ensino médio? Essas indagações instigam a afirmar, na contramão das teorias liberais de justiça social e de cidadania, que o antagonismo de classe, característico das sociedades capitalistas, sustenta e legitima as desigualdades sociais e educacionais em oposição à igualdade e à justiça social.

Segundo Frigotto (2005), em pleno século XXI a escola pública brasileira, em todos os níveis, ainda não conseguiu superar o modelo dualista de educação que historicamente foi sendo construído e consolidado por meio da ação de diferentes governos: uma escola pensada e organizada para atender às camadas populares e outra para atender aos filhos das elites. Nesse contexto, a realidade do ensino médio no Brasil evidencia o tamanho da dívida social que o Estado brasileiro tem com esse nível da educação básica. Dívida expressa na negação do direito ao acesso, à permanência e à aprendizagem, principalmente dos filhos da classe trabalhadora.

O Censo Escolar (BRASIL, 2018), elaborado pelo Instituto Nacional de Estudos e Pesquisas Educacionais Anísio Teixeira (INEP), demostra que a evasão escolar entre os jovens matriculados no ensino médio é alarmante. Das 7,9 milhões de matrículas no ensino médio, em 2017, a taxa de evasão chegou a $12,7 \%$ e a taxa de repetência a $15,2 \%$. A evasão e a repetência são maiores entre os estudantes mais pobres, pretos e pardos. Segundo os dados do IBGE, no ano de 2016 apenas $56,7 \%$ dos jovens concluíram esta etapa da educação básica, $88 \%$ deles em instituições públicas, muitas em condições precárias (péssimas estruturas físicas, ausência de professores e em cursos noturnos). A realidade apreendida pelo Inep e o IBGE é expressão da desigualdade social que se materializa em diferentes espaços sociais, inclusive na escola, como parte constituinte e constitutiva da vida social mais ampla. 
Há, na sociedade brasileira, um tecido estrutural profundamente opaco nas relações de poder e propriedade que se move em conjunturas muito específicas, mas que, no seu núcleo duro, de marca excludente, de subalternidade e de violência, se mantém recalcitrante. Um olhar atento sobre a estrutura de classe e o desenvolvimento histórico do capitalismo no Brasil nos revelará um exemplo emblemático de sociedade que mantém uma estrutura de desigualdade brutal [...] (FRIGOTTO, 2005, p.8).

A desigualdade social, materializada em projeto de nação é, para Florestan Fernandes (1960), constitutiva e constituinte do capitalismo brasileiro. Para ele, a classe dominante, principalmente nos momentos de crises conjunturais, vai se rearticulando como estratégia de conciliação de interesses para manter a hegemonia necessária à reprodução do capital e à manutenção das desigualdades estruturantes. Para Francisco de Oliveira (2003), o desenvolvimento capitalista brasileiro se fundamentou e se alimenta da desigualdade social, portanto alimenta-se da exclusão e da exploração do homem. Seguindo as perspectivas ap resentadas por esses dois estudiosos da sociedade brasileira, é possível afirmar que a escola dualista, da educação básica ou ensino superior, é expressão desta lógica socioeconômica desigual e combinada, estruturante do capitalismo no Brasil.

Segundo Frigotto (2005, p. 31), na história da educação brasileira as políticas e a organização curricular do ensino médio evidenciam, em grande medida, a contradição fundamental entre capital e trabalho que, desde a década de 1970, se repõe e expressa um falso dilema da identidade deste nível de ensino: "formação propedêutica ou preparação para o trabalho?". Como resposta a esse suposto dilema, passando pela Reforma de $1971^{3}$ à Reforma de $2017^{4}$, o ensino médio é/foi alvo de debates e disputas que envolvem concepções de sociedade, educação e formação divergentes e, portanto, antagônicas.

Em meio a essas disputas, os idealizadores das reformas criam o consenso em torno da ideia de que, principalmente para os filhos das camadas populares, o ensino médio tem como sentido e finalidade a preparação técnica para o mercado de trabalho. Por detrás desse consenso está a lógica de que "[...] a formação profissional passa a assumir um importante papel no campo das mediações da prática educativa, no sentido de responder às condições gerais da produção capitalista" (FRIGOTTO, 2005, p. 32). Essa constatação pode ser verificada nas reformas do ensino médio no período de ditadura militar, no Governo de Fernando Henrique Cardoso (1995-2003) e no Governo Lula (20032011) (FERRETI; SILVA, 2017).

Segundo Ferreti e Silva (2017), a ideia de que mudanças na estrutura curricular do ensino médio são necessárias para responder às necessidades e às demandas postas pelo sistema de produção, ganhou centralidade nos discursos e nas ações dos idealizados da Reforma de Ensino, instituída pela Lei n. 13.415 de fevereiro de 2017, sancionada pelo Governo Temer (2016-2018). Desde a Medida Provisória n. 746 de 22 de setembro de 2016, reiterou-se, no âmbito do executivo federal, o discurso de que a Reforma do Ensino, além de favorecer o protagonismo juvenil na escolha do seu itinerário formativo, atenderia às novas exigências sociais do mercado de trabalho. Observou-se que, por meio de uma 
intensa propaganda em diferentes mídias e redes sociais acerca dos supostos benefícios da Reforma do ensino médio, foi-se produzindo consensos e adesões em torno da proposta de reformulação do currículo e da estrutura de organização e funcionamento desse nível de ensino.

As ações reformistas do Governo Temer para educação básica têm sido pautadas na construção de consensos em torno da ideia de que as mudanças são respostas ao anseio da sociedade civil. No caso do ensino médio, criou-se a mística em torno do protagonismo juvenil na escolha de seu próprio itinerário formativo, desconsiderando os limites dos próprios sistemas de ensino em implementar o que a lei determina. Sem um debate profundo, a Reforma do ensino foi apresentada e defendida pelo governo federal como uma estratégia importante para ampliação dos números do acesso, permanência e conclusão desse nível de escolarização e para a melhoria dos resultados dos estudantes no Exame de Avaliação do Ensino Médio (ENEM). Id eologicamente, a política educacional foi tratada como solução para os problemas do ensino médio sem, contudo, apontar e enfrentar as questões sociais externas à escola (formação para a construção da cidadania e problemas como: desemprego, violência urbana, exclusão social, etc) que, dialeticamente, interferem no cotidiano escolar e na permanência do jovem no ensino médio (FERRETI E SILVA, 2017).

Tal perspectiva reforça o que até mesmo os intelectuais do campo liberal criticam, a exemplo de Dubet (2008), de que nas sociedades liberais se produziu um conjunto de ficções que têm por objetivo reduzir as contradições (desigualdade e injustiça) inerentes a essa sociedade. Para 0 autor, a ficção se materializa na medida em que se faz da performance desigual dos alunos o produto de seu próprio mérito, oriundo de sua liberdade e de sua igualdade. Nesse sentido, a ficção mais eficaz consiste em transformar e tratar os resultados escolares dos alunos como consequência direta de seu esforço, de sua coragem, de sua atenção, do seu engajamento livre no trabalho escolar. 0 fracasso, nesse caso, é o resultado direto da falta de trabalho, de atenção e de seriedade dos estudantes.

Numa perspectiva crítica, o que se evidencia é que a ideia de protagonismo juvenil camufla a perversidade de se colocar nos sujeitos a culpa pelo fracasso escolar, oriundo de suas supostas liberdades de escolhas. Essa perversidade manifesta-se no que Bourdieu (2001) classifica como contradição entre esperanças subjetivas e oportunidades objetivas dos agentes.

$\mathrm{Na}$ busca do consenso social, capitaneada pela ideia do protagonismo juvenil e pela qualidade da escola de ensino médio, o Governo Temer apoiou-se em setores empresariais (bancos, indústrias de material didático, empresários da educação) ${ }^{5}$ na busca de adesões junto aos sistemas de ensino. Atualmente, esses setores são os grandes parceiros do governo na implementação da Reforma.

Vale destacar que, no processo de elaboração e apresentação dos pontos centrais da reforma, o Ministério da Educação (MEC) ocultou, ou, de certa forma, negou a importância da participação de professores, entidades de pesquisas, universidades e sindicatos dos trabalhadores da educação no debate em torno da reforma e de suas implicações para a formação da juventude brasileira. Entre os principais pontos da Reforma do Ensino, instituída pela Lei n. 13.415, merecem destaques:

- Ampliação da Jornada Escolar em escolas de tempo integral. Esse nível de ensino passará de 800 horas/anuais para 1.400, mantendo a obrigatoriedade de 
- 2000 dias letivos, conforme já previstos na Lei de Diretrizes e Bases da Educação Nacional (LDB);

- Organização do Currículo escolar por meio de cinco (5) Itinerários Formativos: I) linguagens; II) Matemática; III) Ciências da natureza; IV) Ciências humanas; e V) Formação técnica e profissional. De acordo com o texto da Reforma, os sistemas de ensino poderão compor os seus currículos com base em mais de uma área prevista.

- Obrigatoriedade das disciplinas de Língua Portuguesa, Língua Inglesa e Matemática. As demais disciplinas serão cursadas pelos estudantes, conforme a escolha dos itinerários formativos;

- Autorização do notório saber para exercício da docência no Itinerário Formativo de Formação Técnica e Profissional. Abre-se também a possibilidade dos sistemas de ensino e das escolares estabelecerem parceria com instituições privadas para oferta desse itinerário, conforme poderá ser verificado no Artigo 36, Parágrafos 60 ao $12 \div$

- Aproximação entre o ensino médio e o mercado de trabalho. Os idealizados da reforma apostam que o novo desenho curricular favorecerá a preparação dos jovens, sobretudo das camadas populares para o mercado de trabalho, sem a necessidade de uma formação no ensino superior.

Mesmo em fase de implementação, a Reforma do ensino médio foi/é objeto de críticas e embates expressos em discursos favoráveis e contrários à proposta. Estudiosos de políticas educacionais (FERRETI E SILVA, 2017), considerando o atrelamento do Governo Temer ao ideário neoliberal, alertam quanto às concepções e as implicações da reforma para a escola, educação e a sociedade brasileira. Entre as críticas apresentadas à reforma, ressaltam-se:

- O não enfrentamento dos problemas históricos do ensino médio e da escola pública de educação básica. A Reforma, como foi pensada e está sendo implementada, não enfrenta os problemas históricos e estruturais da escola pública brasileira, tais como: falta de professores habilitados, sobretudo nas áreas de Biologia, Física, Química e Matemática; precariedade da estrutura física das instituições escolares; desvalorização da formação e da profissão docente; pouca atratividade da docência; ausência de políticas públicas que favoreçam a permanência dos jovens da classe trabalhadora na escola de tempo integral; melhoria da qualidade do ensino fundamental ( 1 ㅇ ao 9 o ano); universalização da educação infantil.

- A ausência de participação popular na elaboração da proposta. A proposta, na fase de elaboração e aprovação, não foi objeto de discussão e de consulta pública. Todo o processo foi caracterizado pela ausência de participação de professores, alunos e de instituições de ensino superior de formação docente. 
- O atrelamento do ensino médio ao mercado de trabalho. Discurso hegemônico aliado e articulado às demandas e à lógica de mercado, sobretudo no que se refere ao sentido e à finalidade do "Itinerário de Formação Técnica".

- A Hegemonia de determinadas disciplinas em detrimento de outras. Desvalorização das disciplinas, sobretudo da área de humanas, artes e educação física. Uma perspectiva curricular que negligencia ou nega a importância das ciências humanas e das linguagens artísticas e corporais na formação dos estudantes, numa proposta de escola de período integral que se diz comprometida com a formação integral dos sujeitos.

- A padronização de um modelo único de ensino médio por meio de uma orientação curricular que desconsidera a realidade socioeconômica das diferentes regiões brasileiras. A transformação do ensino médio numa mercadoria disputada pelo mercado nacional e internacional de educação, representada por grupos empresariais com experiência no investimento financeiro no ensino superior.

- A desvalorização da formação e da profissão docente. Ao permitir que professores com notório saber assumam a regência de sala no ensino médio, no Itinerário de Formação Técnica, o governo, de certa forma, legitima a contratação de leigos para o exercício da docência, desconsiderando as lutas e as conquistas históricas da categoria na defesa da formação e da profissão docente.

- O pouco investimento financeiro do governo federal para custear a implementação da proposta. Até o momento, o governo federal ainda não apresentou quais fontes de recursos financiaram a reforma do ensino médio em escolas de tempo integral, considerando que, por meio da Emenda Constitucional n. 95 (BRASIL, 2017), o governo federal congelou os gastos públicos, principalmente nas áreas sociais (educação, saúde, previdência, seguridade e assistência social) por vinte (20) anos. Dessa forma, nos induz a afirmar que os sistemas públicos de educação se adequarão às determinações da lei de forma improvisada e precária, portanto, na contramão da qualidade anunciada pelos reformadores.

- A ausência de diretrizes para a organização curricular das escolas de ensino médio, considerando a gradativa ampliação da jornada escolar. Ressalta-se que, até o momento, o MEC não conseguiu apresentar a Base Nacional Comum Curricular (BNCC) para o ensino médio.

- A formação técnica e profissional como solução para empregabilidade dos jovens pobres, em detrimento da formação integral e interdisciplinar. A formação técnica como marco da terminalidade da escolarização deste grupo social.

- A ocultação da relação entre a desigualdade social e desigualdade educacional. Pesquisas evidenciam (CIAVATTA, 2005; FRIGOTTO, 2005) que a desigualdade social implica diretamente 0 acesso, na permanência e a na aprendizagem do jovem das camadas populares no ensino médio. Contudo, os idealizadores da reforma apostam nas capacidades individuais dos sujeitos para alcançar os objetivos anunciados, não expressando nenhuma preocupação com a 
construção da cidadania e da justiça social, mesmo que dentro de uma perspectiva liberal clássica.

Essas críticas, mesmo considerando que a Reforma do Ensino Médio ainda esteja em processo de implementação, evidenciam que as políticas educacionais do Governo Temer, mesmo que precedidas por um discurso de qualidade em educação, protagonismo juvenil e justiça social, estão inseridas e articuladas a uma lógica capitalista de sociedade e de Estado neoliberal. Nesta lógica, o Estado deve ser mínimo para as demandas da área social e máximo para o capital, sobretudo o financeiro mundializado, por conseguinte, na contramão da justiça social liberal e bem distante da ideia de emancipação humana defendida pelos pensadores críticos da educação.

Para Frigotto (2017), a Reforma

[...] expressa e consolida o projeto da classe dominante brasileira em sua marca antinacional, antipovo, antieducação pública, em suas bases político-econômicas de capitalismo dependente, desenvolvimento desigual e combinado, que condena gerações ao trabalho simples e nega os fundamentos das ciências que permitem aos jovens entender e dominar como funciona o mundo das coisas e a sociedade humana. Uma violência cínica de interdição do futuro dos filhos da classe trabalhadora por meio da oficialização da dualidade intensificada do Ensino Médio e de uma escola esvaziada, na perspectiva de Antônio Gramsci (2017, p. 368).

Assim, a reforma do ensino médio em curso, considerando as bases teóricas e políticas que a sustentam, não tem potencialidade pedagógica para contribuir com a formação integral e integradora dos sujeitos, nem mesmo para uma formação de sujeitos para a construção da cidadania e da justiça social. Para Ciavatta (2005, p. 98),

0 primeiro pressuposto da formação integrada é a existência de projeto de sociedade no qual, ao mesmo tempo, se enfrente os problemas da realidade brasileira, visando a superação do dualismo de classes, e as diversas instâncias responsáveis pela educação (governo federal, secretariais de educação, direção das escolas e professores) manifestem a vontade política de romper com a redução da formação à simples preparação para o mercado de trabalho.

Uma proposta de ensino médio, fundamentada numa perspectiva crítica e emancipadora do homem, que prepare os sujeitos para o exercício da cidadania e para sua prática produtiva no mundo trabalho (e não meramente para o mercado), necessariamente deverá estar articulada a um projeto de sociedade democrática e igualitária. Nessa direção, Frigotto (2005) afirma que uma proposta de ensino médio que integre conhecimentos científico-culturais e a prática de trabalho

[...] busca romper com a dicotomia entre educação básica e técnica, resgatando o princípio da formação humana em sua totalidade; em termos epistemológicos e pedagógicos, esse ideário defendia um ensino que integrasse ciência e cultura, humanismo e tecnologia, visando ao desenvolvimento de todas as potencialidades 
humanas. Por essa perspectiva, o objetivo profissionalizante não teria fim em si mesmo nem se pautaria pelos interesses do mercado, mas constituir-se-ia numa possibilidade a mais para os estudantes na construção de seus projetos de vida, socialmente determinados, possibilitados por uma formação ampla e integral (p. 36).

Nesse projeto emancipatório de sociedade e de formação humana, os conhecimentos escolares são os meios para a formação integral dos estudantes num movimento de articulação da educação formal à prática social e ao mundo trabalho. Contudo, de acordo com Frigotto (2005), a adequação do Estado brasileiro, na década de 1990, à lógica de gestão e regulação neoliberal, teve incidência direta na organização da educação escolar, impulsionando um processo de exclusão social dos jovens pobres à educação básica. No âmbito das políticas educacionais, a Reforma do Ensino médio do Governo Temer, premida também pela lógica neoliberal, contribuiu para agudizar ainda mais o processo de exclusão dos jovens trabalhadores desse nível de ensino, corroborando com a tese de que as políticas neoliberais caminham na contramão da igualdade social e que, portanto, ao contrário do que Rawls (2000) defendia, é impossível, numa sociedade mercado, a garantia da justiça social.

\section{CONSIDERAÇÕES FINAIS}

De forma geral, consta-se que a Reforma do Ensino Médio, a partir da lógica neoliberal anunciada e assumida, não tem, em seu arcabouço ideológico e prático, o compromisso com a ampliação da participação popular e com a responsabilização do Estado na distribuição dos bens materiais e simbólicos produzidos pela sociedade. Contudo, uma análise mais rigorosa no campo das políticas educacionais confirma o caminho inverso, qual seja, o da exclusão da maioria da população do acesso a tais bens. Nesse projeto de Estado e de sociedade, sintetizado no texto da Reforma (BRASIL, 2017), o modelo de formação escolarnecessariamente deve estar voltado para o fornecimento de mão-de-obra técnica para o mercado de trabalho e para adequação e aceitação do trabalhador à lógica da precarização das relações de trabalho e do desemprego estrutural.

Nessa perspectiva, o que está em questão é como a educação básica poderá estar a serviço da preparação de sujeitos que atendam às novas demandas do mercado, inclusive por meio do desemprego e do consumo. Não se trata, logo, de incluir a população nos benefícios materiais e simbólicos produzidos pelo mundo global, mas de evitar que parte dela se constitua numa classe perigosa, em um mundo de desemprego, de precarização do trabalho, de racismos, xenofobismos e várias formas de injustiças sociais, ou seja, de evitar que os excluídos tomem consciência de sua exclusão e se constituam como agentes coletivos de transformação.

Educar para a construção da cidadania, da justiça social e para a práxisno mundo do trabalho, numa perspectiva crítica e emancipatória de educação e de sociedade, exige o enfrentamento, no âmbito do Estado brasileiro, da extrema desigualdade social que interfere direta ou indiretamente no processo de escolarização das camadas populares. Caso contrário, as reformas não passarão de retóricas para ocultação da real materialidade histórica marcada pela exclusão e exploração do homem pelo homem. 
SOCIAL INEQUALITY AND THE RIGHT TO EDUCATION IN BRAZIL: REFLECTIONS FROM THE HIGH SCHOOL REFORM

\begin{abstract}
This study aims to analyze the political and pedagogical implications of the Reform of Secondary Education in Brazil, instituted by Law n. 13,415 of February 2017, and the guarantee of the right to education, considering the interfaces between social inequality and educational inequality. In order to do so, we sought to understand, in the field of social theories, the discussions around the concept of social justice, citizenship and the right to education, taking as reference the studies of Anderson (2002), Bourdieu (2001), Ciavatta; Dubet (2008), Fernandes (1960), Frigotto (2005; 2017), Marshal (1988), Marx (2010), Oliveira (2003), Rawls (2000).
\end{abstract}

KEYWORDS: Social inequality. Right to education. High School Reform.

\title{
DESIGUALDAD SOCIAL Y EL DERECHO A LA EDUCACIÓN EN BRASIL: REFLEXIONES A PARTIR DE LA
} REFORMA DE LA ENSEÑANZA MEDIA

RESUMEN: Este estudio tiene por centralidad analizar las implicaciones políticas y pedagógicas de la Reforma de la Enseñanza Media en Brasil, instituida por la Ley n. 13.415 de febrero de 2017, y la garantía del derecho a la educación, considerando las interfaces entre la desigualdad social y la desigualdad educativa. Para ello, se buscó aprehender, en el campo de las teorías sociales, las discusiones en torno al concepto de justicia social, ciudadanía y derecho a la educación, tomando como referencia los estudios de Anderson (2002), Bourdieu (2001), Ciavatta; Dubet (2008), Fernández (1960), Frigotto (2005; 2017) Marshal (1988), Marx (2010), Oliveira (2003), Rawls (2000).

PALABRAS CLAVE: Desigualdad social. Derecho a la educación. Reforma de la Enseñanza Media.

\section{NOTAS}

1) O inglês T. H. Marshal, em 1949, desenvolve uma importante definição sobre cidadania e, em mais de seis décadas, o seu ensaio continua sendo uma referência teórica importante para quem pretende refletir sobre a cidadania na sociedade contemporânea.

2) Vale ressaltar que, Marshall (1988) analisa a experiência do Welfare State como uma espécie de fim humanista da história.

3) Ler: Germano (2011). 
GOMES, M. P.; DUARTE, A. J.

4) Verificar: Ferreti e Silva (2017) sobre as disputas de projetos em torno do ensino médio do Governo de Fernando Henrique Cardoso (1995-2003) ao Governo Temer (2016-2018).

5) Segundo Cerasoli (2017), a Reforma do Ensino encontrou respaldo, sobretudo nos discursos e nas ações do Movimento Todos pela Educação, movimento integrado pela Fundação Lemann, Itaú Social, Fundação Bradesco, Organizações Globo, Instituto Unibanco, Grupo Gerdau, Fundação Roberto Marinho, Instituto Ayrton Senna, entre outros.

\section{REFERÊNCIAS}

ADORNO, T; HORKHEIMER, M. Dialética do esclarecimento. Rio de Janeiro: Zahar, 1985.

ANDERSON, P. Afinidades Seletivas. São Paulo: Boitempo editorial, 2002.

BOURDIEU, P. O ser social, o Tempo e o Sentido da existência. In: BOURDIEU, P. Meditações pascalinas. Tradução de Sergio Miceli. Rio de J aneiro: Bertrand Brasil, 2001.

BRASIL. Lei 13.415, de 16 de fevereiro de 2017. Altera as Leis nos 9.394, de 20 de dezembro de 1996, que estabelece as diretrizes e bases da educação nacional, e 11.494, de 20 de junho 2007, que regulamenta o Fundo de Manutenção e Desenvolvimento da Educação Básica e de Valorização dos Profissionais da Educação, a Consolidação das Leis do Trabalho - CLT, aprovada pelo Decreto-Lei o․ 5.452, de 10 de maio de 1943, e o DecretoLei o 236, de 28 de fevereiro de 1967; revoga a Lei no11.161, de 5 de agosto de 2005; e institui a Política de Fomento à Implementação de Escolas de Ensino Médio em Tempo Integral. Brasília: Presidência da República, 2017.

. Censo Escolar 2017. Brasília: INEP, 2018.

CIAVATTA, M. A formação integrada: a escola e o trabalho como lugares de memória e de identidade. In: FRIGOTTO, G., CIAVATTA, M., RAMOS, M. Ensino Médio Integrado: concepção e contradições. São Paulo: Cortez, 2005.

CERASOLI, J. F. Educação Sitiada: articulações e estratégias em torno da BNCC. 28 out. 2017. 27 slides. Material apresentado em palestras para o Pibid PUC Goiás.

DUBET, François. O que é uma escola justa. São Paulo: Editora Cortez, 2008.

FERNANDES, F. Mudanças sociais no Brasil: Aspectos do desenvolvimento da sociedade brasileira. São Paulo: DIFEL, 1960.

FERRETI, C. J.; SILVA, M. R. A Reforma do Ensino Médio no contexto da Medida Provisória n. 746/2016: Estado, Currículo e Disputas. Educ. Soc., Campinas, v. 38, n. 139, p. 385-4004, abr./jun., 2017. 
Desigualdade social e o direito à educação...

FRIGOTTO, G. Educação e Crise do Trabalho: perspectivas de final de século. Petrópolis: Vozes, 1994.

. Concepções e mudanças no mundo do trabalho e o ensino médio. In: FRIGOTTO, G., CIAVATTA, M., RAMOS, M. Ensino Médio Integrado: concepção e contradições. São Paulo: Cortez, 2005.

Por que a urgência da reforma do ensino médio? Educ. Soc., Campinas, v. 38, no 139, p.355-372, abr./jun., 2017.

GERMANO, José Willington. Estado militar e educação no Brasil (1964-1985). São Paulo: Cortez, 2011.

MARSHAL, T. H. Cidadania e Classe Social. Brasília: Fundação Rondon, 1988.

MARX, K. Sobre a questão judaica. Trad. Nélio Schneider. São Paulo: Boitempo, 2010.

OLIVEIRA, F. Crítica à razão dualista/O ornitorrinco. São Paulo: Boitempo, 2003.

RAWLS, J. Uma teoria da justiça. São Paulo: Martins Fontes, 2000.

Marcilene Pelegrine Gomes: Doutora em Educação. Professora Adjunta da Universidade Federal de Goiás. Áreas de pesquisa: Políticas Educacionais para Educação Básica; Currículo e Avaliação; Educação para Relações Étnico-Raciais.

E-mail: pelegrine10@yahoo.com.br

Aldimar Jacinto Duarte: Doutor em Educação. Professor Adjunto da Pontifícia Universidade Católica de Goiás. Professor no Programa de Pós-Graduação em Educação da PUC Goiás. Área de pesquisa: Juventude, Estado e Cultura, Movimentos Sociais.

E-mail: aldimarjd@hotmail.com

Este periódico utiliza a licença Creative Commons Attribution 3.0, para periódicos de acesso aberto (Open Archives Iniciative - OAI). 